\title{
Dampak Pembangunan Jalan Desa Terhadap Kondisi Sosial Masyarakat
}

\author{
${ }^{*}$ Rini Mastuti ${ }^{1)}$, Abdul Chalik ${ }^{2)}$, Toti Sindra Kurniawan ${ }^{3)}$, Natasha ${ }^{4)}$
}

Program Studi Agribisnis, Fakultas Pertanian, Universitas Samudra

Correspondence author: rinimastuti@unsam.ac.id

Received : 21 Mei 2021

Accepted : 23 September 2021

Published: 30 September 2021

DOI: https://doi.org/10.37012/jpkmht.v3i2.555

\begin{abstract}
ABSTRAK
Penelitian ini dilakukan di Desa Simpang Empat, Kabupaten Asahan.Tujuan dari penelitian adalah untuk mengetahui dampak pembangunan infrastruktur jalan terhadap perubahan kondisi sosial yang terjadi di masyarakat, karena pembangunan infrastruktur jalan merupakan sarana yang paling mendasar yang bertujuan untuk mendukung kelancaran arus transportasi, distribusi dan koneksi. Pengumpulan data dilakukan menggunakan kuisioner, observasi dan studi pustaka. Analisis penelitian menggunakan metode deskriptif kualitatif. Hasil penelitian menunjukkan bahwa pembangunan infrastruktur jalan di Desa Simpang Empat merupakan program revitalisasi fungsi transportasi yang dilakukan sesuai standar Kementrian PUPR. Pelaksanaan proyek pembangunan fisik jalan melibatkan partisipasi aktif masyarakat sebagai tenaga kerja dengan menggunakan sumber daya setempat. Pembagunan jalan tersebut memberikan dampak yang positif terhadap perubahakan kondisi sosial masyarakat.
\end{abstract}

Kata Kunci: Pembangunan, Jalan, Masyarakat, Sosial.

\begin{abstract}
This research was conducted in Simpang Empat Village, Asahan Regency. The purpose of the study was to find out the impact of road infrastructure development on changes in social conditions that occur in the community because the construction of road infrastructure is the most basic means that aims to support the smooth flow of transportation, distribution, and connection. Data collection is done using questionnaires, observations, and library studies. The research analysis uses qualitative descriptive methods. The results showed that the construction of road infrastructure in Simpang Empat Village is a program to revitalize transportation functions carried out by the standards of the Ministry of PUPR. The implementation of road physical development projects involves the active participation of the community as a workforce using local resources. The construction of the road has a positive impact on the change of social conditions of the community.
\end{abstract}

Keywords: Development, Roads, Communities, Social. 


\section{PENDAHULUAN}

Hampir separuh penduduk Indonesia tinggal di pedesaan dan menurut Sri Mulyani menjadi tanggung jawab bersama untuk merumuskan strategi penanganan penyediaan infrastruktur perdesaan yang dapat mendukung terjaminnya peningkatan ekonomi dan kesejahteraan masyarakat desa (Anggraeni, 2021). Pembangunan merupakan proses perbaikan yang berkesinambungan pada suatu masyarakat menuju kehidupan yang lebih baik atau lebih sejahtera. Terdapat beberapa cara untuk menentukan tingkat kesejahteraan pada suatu negara, yang dilakukan melalui upaya-upaya secara sadar dan terencana (pembangunan). Pada sebagian besar masyarakat, pembangunan selalu diartikan sebagai perwujudan fisik. Bahkan, pembangunan dimaknai secara khas, seperti makna kata pembangunan secara fisik contohnya pembangunan mall, jembatan, jalan raya, rumah ibadah, dan sebagainya (Drajat Kartono and hanif Nurcholis, 2016). Pembangunan di wilayah desa, pada dasarnya adalah untuk meningkatkan kesejahteraan warga desa.

Pada Peraturan Menteri Dalam Negeri No. 114 Tahun 2014 (Permendagri, 2014) tentang Pedoman Pembangunan Desa disebutkan bahwa, perencanaan pembangunan desa merupakan tahapan kegiatan yang diselenggarakan oleh Pemerintah Desa dengan melibatkan Badan Permusyawaratan Desa dan unsur masyarakat lainnya secara partisipatif guna pemanfaatan dan pengalokasian sumber daya desa untuk mencapai tujuan pembangunan desa. Dengan kondisi tersebut diharapkan pembangunan mendapatkan dukungan positif dan berjalan secara berkelanjutan.

Menurut Kementerian Desa Pembangunan Daerah Tertinggal, dan Transmigrasi Republik Indonesia, pembangunan partisipatif adalah suatu sistem pengelolaan pembangunan di desa dan kawasan perdesaan yang dikoordinasikan oleh kepala Desa dengan mengedepankan kebersamaan, kekeluargaan, dan kegotongroyongan guna mewujudkan pengarusutamaan perdamaian dan keadilan sosial (Kemendes, 2020). Pembangunan desa mencakup bidang penyelenggaraan pemerintahan desa, pelaksanaan pembangunan desa, pembinaan kemasyarakatan desa dan pemberdayaan masyarakat desa. Salah satunya adalah pembangunan prasarana transportasi darat yakni jalan lingkungan. Pembangunan infrastruktur jalan merupakan sarana yang paling mendasar yang bertujuan untuk mendukung kelancaran, distribusi barang, maupun jaringan transportasi manusia (Sasmito, 2017). Jalan lingkungan merupakan jalan umum yang berfungsi melayani angkutan lingkungan dengan ciri perjalanan jarak dekat dan kecepatan rata-rata rendah. Pembangunan jalan lingkungan merupakan bagian dari pembangunan infrastruktur desa berbasis masyarakat (Kessa, 2015). Masyarakat 
menggunakan jalan lingkungan dan gang sebagai sarana pendukung transportasi dan ruang interaksi sosial.

Desa Simpang Empat terletak di wilayah pusat Kecamatan Simpang Empat, Kabupaten Asahan. Pada daerah ini sedang dilakukan pembangunan desa yaitu perbaikan infrastruktur jalan yang merupakan jalur akses pada pendidikan, pemerintahan, ekonomi sekaligus menjadi tempat interaksi sosisal bagi masyarakat sekitar. Kondisi fisik jalan di Desa Simpang Empat, mengalami kerusakan yang ringan sampai parah seperti tidak rata, pecah dan berlubang yang menyebabkan pengemudi harus pelan-pelan saat melalui jalan tersebut supaya tidak mengalami kecelakaan dan lebih nyaman. Pada musim penghujan jalan tersebut tergenang air sehingga mengganggu keamanan dan kelancaran arus transportasi. Konsidi tersebut menyebabkan waktu tempuh lebih lama, mengurangi kenyamanan berkendara serta mempercepat kerusakan kendaraan serta mempengaruhi dan menghambat proses interaksi sosial masyarakat. Terkait kondisi jalan tersebut maka Pemerintah Desa Simpang Empat menyusun strategi pembangunan jalan dengan melibatkan partisipasi aktif warga. Tujuan dari penelitian adalah untuk mengetahui dampak pembangunan infrastruktur jalan desa terhadap perubahan kondisi sosial yang terjadi di masyarakat.

\section{METODE PELAKSANAAN}

Penelitian dilakukan di Desa Simpang Empat Kabupaten Asahan selama 1 bulan dengan pendekatan statistik non parametrik. Analisis penelitian menggunakan analisis deskriptif kualitatif karena data yang diperoleh berupa kata, kalimat, skema dan gambar (Sugiyono, 2015). Data primer diperoleh dari hasil jawabab wawancara dan pengisian kuisioner oleh responden. Sedangkan data sekunder berupa dokumen-dokumen yang berkaitan dengan pelaksaaan proyek pembangunan infrastruktur jalan desa.

Metode analisis data yang dilakukan melalui prosedur dan tahapan-tahapan berikut:

\section{Pengumpulan data}

Proses pengumpulan data dari lapangan diawali dengan memasuki lokasi penelitian. Dalam hal ini peneliti mendatangi tempat penelitian, yaitu Desa Simpang Empat, Kabupaten Asahan. Kemudian dilanjutkan dengan menemui orang-orang yang ditarget sebagai informan penelitian. Pada proses selanjutnya adalah pengumpulan data dengan teknik wawancara, mengisi kuisioner dan observasi untuk memperoleh informasi yang dibutuhkan. 


\section{Reduksi data}

Reduksi data merupakan pemilihan data dan pemusatan perhatian kepada data-data yang betul-betul dibutuhkan sebagai data utama dan memilah data yang sifatnya hanya pelengkap saja. Data yang diperoleh dari lokasi penelitian atau data lapangan dituangkan dalam uraian atau laporan yang lengkap dan terinci. Laporan lapangan direduksi dan dirangkum.

\section{Klasifikasi data}

Data yang telah terkumpul selama penelitian kemudian dikelompokkan sesuai dengan tujuan penelitian. Hasil klasifikasi data selanjutnya di sistematisasikan dengan menyajikan data-data.

\section{Penyajian data}

Penyajian data dimaksudkan agar memudahkan bagi peneliti untuk melihat gambaran secara keseluruhan atau bagian-bagian tertentu dari penelitian.

\section{Penarikan kesimpulan}

Setelah melakukan penyajian data maka kesimpulan awal dapat dilakukan. Penarikan kesimpulan ini juga dilakukan selama penelitian berlangsung. Sejak awal kelapangan serta dalam proses pengumpulan data peneliti berusaha melakukan analisis dan mencari makna dari yang telah terkumpulkan.

\section{HASIL DAN PEMBAHASAN}

\section{Karakteristik Desa Simpang Empat}

Desa Simpang Empat terletak di Kecamatan Simpang Empat, Kabupaten Asahan memiliki luas wilayah 1.770,97 Ha. Adapun batas administratif kawasan studi adalah :

- Sebelah Utara dan Timur berbatasan dengan Desa Perkebunan Sukaraja

- Sebelah Selatan berbatasan dengan Desa Silomlom

- Sebelah Barat berbatasan dengan Desa Perkebunan Hessa.

Jumlah penduduk Desa Simpang Empat adalah 15.837 jiwa dengan persebaran penduduk berdasarkan jenis kelamin yakni : 6.932 jiwa (Laki-laki) dan 8.905 jiwa (Perempuan). Jenis penggunaan lahan terbesar di Desa Simpang Empat berada pada sektor perkebunan kelapa sawit dengan luas wilayah $446 \mathrm{Ha}$ dan penggunaan lahan terkecil berupa perkebunan kakao (coklat) dengan luas wilayah $1 \mathrm{Ha}$. Persebaran keadaan ekonomi masyarakat desa didominasi oleh wiraswasta dan para pedagang. Potensi Desa Simpang Empat untuk sektor pertanian adalah jagung, palawija, tebu, coklat, sawit, karet, kelapa, dan singkong. Potensi Desa Simpang Empat untuk sektor peternakan meliputi kambing, sapi, kerbau, ayam, dan itik. 


\section{Pembangunan Jalan Rabat Beton}

\section{Persiapan Konstruksi Pembangunan Jalan Rabat Beton}

Dalam proses pelaksanaan konstruksi dibutuhkan sumber daya manusia yang mampu mengkoordinir pelaksanaan konstruksi melalui pembentukan struktur organisasi Tim Pengelola Kegiatan (TPK) Desa Simpang Empat dengan uraian tugas masing-masing yang meliputi :

(1) Ketua Pelaksana

(2) Sekretaris

(3) Bendahara

(4) Divisi Perencanaan

(5) Divisi Pelaksanaan

(6) Divisi Pengawasan
: Yafitham Marpaung

: Ahmad Fauji. A.Md. Kom

: Ade Sumantri

: Fadli

: Syahbudi

: Ikka Rahmatika

Pelibatan masyarakat perdesaan dalam pembangunan infrastruktur perdesaan akan memberikan beberapa dampak, antara lain (1) kualitas pekerjaan yang dihasilkan, (2) keberlangsungan operasional dan pemeliharaan infrastruktur tersebut, (3) kemampuan masyarakat dalam membangun suatu kemitraan dengan berbagai pihak, serta (4) penguatan kapasitas masyarakat untuk mampu mandiri memfasilitasi kegiatan masyarakat dalam wilayahnya (Asnudin, 2010).

\section{Pelaksanaan Konstruksi Pembangunan Jalan Rabat Beton}

Pembangunan Jalan Rabat Beton yang mengarah kepada standart penerapan konstruksi oleh Kementerian Pekerjaan Umum dan Perumahan rakyat. Pelaksanaan pembangunan jalan rabat beton perkerasan kaku (regid) tersusun dari bahan semen, pasir, kerikil. Konstruksi ini dipakai di daerah dengan struktur tanah labil, mudah pecah, lembek dan pada turunan/ tanjakan diatas singkapa batu. Kulitas campuran 1pc : 2ps : $3 \mathrm{kr}$. Pendekatan perbandingan Volume 1 pengki semen : 2 pengki pasir: 3 pengki kerikil (split). Pelaksanaan swakelola oleh TPK meliputi kegiatan persiapan, pelaksanaan, pengawasan, penyerahan, pelaporan, dan pertanggungjawaban hasil pekerjaan.

Pelaksanaan pembangunan jalan rabat beton meliputi :

- Jadwal pelaksanaan pekerjaan : Agustus-September 2020

- Lokasi konstruksi : : Desa Simpang Empat

- Ukuran : 105 meter

- Penggunaan tenaga kerja $\quad: 12$ pekerja 
- Rencana Anggaran Biaya (RAB) : Rp. 57.397.200.-

\section{Persyaratan material :}

- Pasir maupun krikil harus bebas dari bahan lain seperti tanah lempung, sampah, dan kotoran lainnya.

- $\quad$ Krikil harus keras dengan bidang pecah minmal 3 bidang.

- $\quad$ Tebal konstruksi $15 \mathrm{~cm}$

- $\quad$ Fas (Faktor air semen) kecil / proses pencampuran penggunaan air jangan terlalu banyak.

\section{Peralatan :}

- Damp truk - Kereta dorong

- Stamper - Timbris

- Beton molen - Sekop

- Sapu lidi - Sendok plester

\section{Kondisi cuaca yang diizinkan untuk bekerja :}

Campuran beton hanya boleh dihampar di permukaan kering, tidak turun hujan, dan permukaan yang disiapkan telah padat dan membentuk punggung sapi (camber) dengan kemiringan 4-5\%.

\section{Pelaksanaan :}

- Permukaan tanah dibentuk punggung sapi

- Pasir urug dihampar setebal $5 \mathrm{~cm}$ dan dipadatkan dengan menyiram air

- Dipasang papan cetakan untuk membatasi ketebalan yang disaratkan dan pemasangan plastik

- Adukan beton dituang ke permukaan dan dipadatkan dengan penggetar atau ditusuktusuk dengan kayu

- Permukaan dibuat kasar dengan menggunakan sapu lidi ke arah menyamping

- $\quad$ Beton curing (Penyiraman beton) selama 28 hari

- Pemakaian setelah umur beton minimal 28 hari dihitung dari akhir pengecoran.

Infrastuktur jalan merupakan awal penggerak pembangunan ekonomi. Pentingnya pembangunan infrastuktur adalah untuk menyediakan lapangan kerja, mempengaruhi dan menentukan integrasi sosial ekonomi rakyat antar wilayah, serta untuk membuka isolasi fisik dan nonfisik pada sejumlah wilayah (Lestari, 2015). 
Hasil analisis data menunjukkan pembangunan jalan rabat beton, sangat memperhatikan kualitas sesuai yang diterapkan Pemerintah Pusat. Hasil pekerjaan rabat beton yang dikerjakan masyarakat cukup baik, karena kualitasnya sesuai dengan standart. Pembangunana jalan desa merupakan revitalisasi fungsi transportasi jalan desa yang dapat dikategorikan sebagai jalan dengan fungsi lokal di daerah perdesaan. Arti fungsi lokal daerah perdesaan yaitu : sebagai penghubung antar desa atau ke lokasi pasar, pendidikan dan fasilitas umum lainnya, sebagai penghubung pemukiman, serta sebagai penghubung wilayah desa ke wilayah lain.

Menurut (NSS, Suryawardana and Triyani, 2015), Infrastruktur adalah secara umum meliputi fasilitas-fasilitas publik yang disiapkan oleh pemerintah sebagai pelayanan publik untuk menunjang dan mendorong aktivitas ekonomi maupun sosial suatu masyarakat seperti jalan, jembatan, terminal, pasar dan prasarana pendidikan serta kesehatan yang dapat mendukung tercapainya kehidupan yang layak bagi masyarakat pedesaan baik material maupun spiritual. Pembangunan jalan rabat beton yang dilakukan di Desa Simpang Empat merupakan kunci keberhasilan program pembangunan berbasis masyarakat dengan memperhatikan berbagai aspek berikut :

- Menggunakan tenaga kerja setempat

- Mengutamakan bahan setempat

- Membangun prasarana yang sederhana, agar dapat dikerjakan oleh masyarakat setempat tanpa mendatangkan tenaga ahli atau peralatan dari luar.

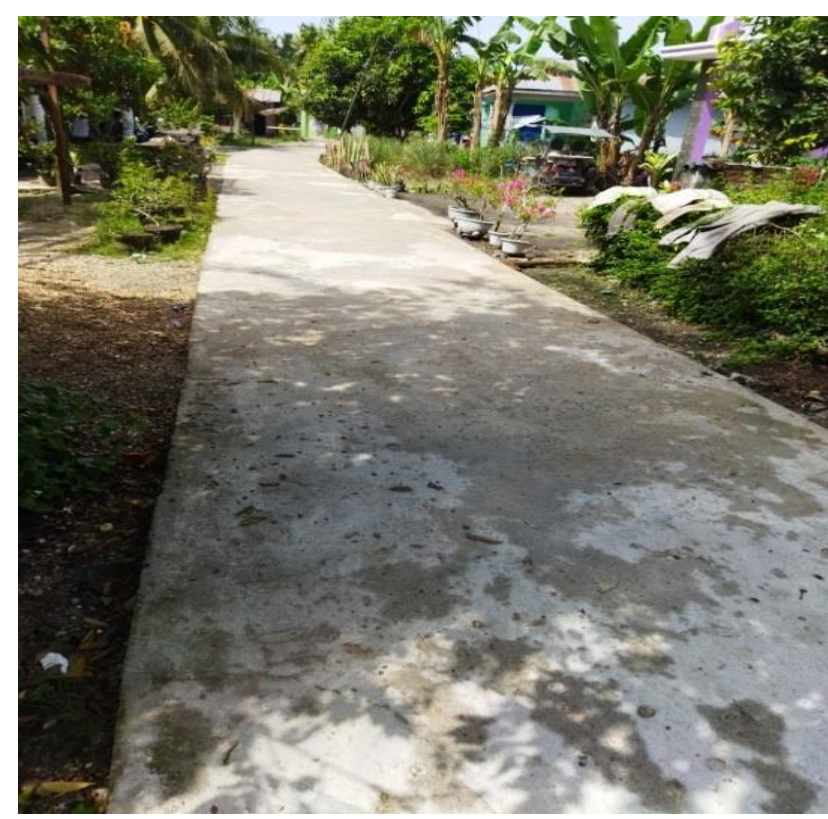

Gambar 1. Pembangunan Jalan Rabat Beton Desa Simpang Empat 
Menurut (Latif, Rusdi and Setiawan, 2020) Partisipasi masyarakat dalam pelaksanaan pembangunan desa harus diartikan sebagai pemerataan sumbangan masyarakat dalam bentuk tenaga kerja,uang tunai, dan atau beragam bentuk korban lainnya yang sepadan dengan manfaat yang akan diterima oleh masing- masing warga.

Pembangunan pada dasarnya memiliki dampak yang menyertainya. Hasil penelitian yang dilakukan Iek (2013) menyatakan bahwa dampak pembangunan jalan di Papua Barat adalah mendorong masyarakat melakukan usaha-usaha ekonomi dengan tujuan meningkatkan pendapatan keluarga akibat akses jalan yang mudah dan murah, terjadinya peningkatan pendapatan riil masyarakat, terjadinya efisiensi waktu dan biaya perjalanan ke dan dari pusat pelayanan ekonomi dan sosial, akses jalan telah memberikan efek berantai yang positif dan signifikan bagi masyarakat (Iek, 2013).

Pembangunan infrastruktur jalan di Desa Simpang Empat memiliki dampak kondisi sosial yang lebih positif pada masyarakat. Dampak positif tersebut antara lain frekuensi interaksi antar warga menjadi lebih sering dan lebih erat, terjadinya pengehematan waktu tempuh perjalanan, kondisi mesin kendaraan menjadi lebih baik serta mendukung dilaksanakan kegiatan sosial masyarakat yang menggunakan badan jalan seperti hajatan dan musyarawah. Menurut (Sedia, 2021), Manfaat penting dari pembangunan sarana transportasi antara lain : berkurangnya biaya eksploitasi, mendorong pembangunan ekonomi, menghemat waktu bagi penumpang dan angkutan barang, berkurangnya kerusakan dan kecelakaan serta bertambahnya kenyamanan pengguna jalan

\section{SIMPULAN}

Hasil penelitian menunjukkan bahwa pembangunan infrastruktur jalan di Desa Simpang Empat merupakan program revitalisasi fungsi transportasi yang dilakukan sesuai standar Kementrian PUPR. Pelaksanaan proyek pembangunan fisik jalan melibatkan partisipasi aktif masyarakat sebagai tenaga kerja dengan menggunakan sumber daya setempat. Pembangunan jalan tersebut memberikan dampak yang lebih positif terhadap kondisi sosial masyarakat.

\section{REFERENSI}

1. Anggraeni, R. (2021) Sri Mulyani: Separuh Penduduk Indonesia Tinggal di Pedesaan, Okezone. Available at: https://economy.okezone.com/read/2021/01/15/320/2345124/sri-mulyani-separuhpenduduk-indonesia-tinggal-di-pedesaan (Accessed: 15 September 2021). 
2. Asnudin, A. (2010) 'Pendekatan Partisipatif Dalam Pembangunan Proyek Infrastruktur Perdesaan di Indonesia', Jurnal SMARTek, 8(3).

3. Drajat Kartono and hanif Nurcholis (2016) 'Konsep dan Teori Pembangunan', Pembangunan Masyarakat Desa dan Kota, IPEM4542/M, pp. 1-52.

4. Kemendes (2020) Peraturan Mentri Desa, Pembangunan Daerah Tertinggal dan Transmigrasi RI Nomor 19 Tahun 2020.

5. Kessa, W. (2015) Perencanaan Pembangunan Desa. Kementrian Desa, Pembangunan Daerah Tertinggal dan Transmigrasi Republik Indonesia.

6. Latif, A., Rusdi, M. and Setiawan, D. (2020) 'Partisipasi Masyarakat Terhadap Pembangunan Infrastruktur Jalan Tani Desa Teteaji Kecamatan Tellu Limpoe Kabupaten Sidenreng Rappang', PRAJA: Jurnal Ilmiah Pemerintahan, 8(1). doi: 10.51817/prj.v8i1.209.

7. Lestari, E. P. (2015) 'Implemetasi Kebijakan Pembangunan Infrastruktur Perdesaan (Studi Pada Pavingisasi Jalan Desa Di Kecamatan Dander Kabupaten Bojonegoro)', Jurnal Administrasi Publik Mahasiswa Universitas Brawijaya, 3(5).

8. NSS, R. L. P., Suryawardana, E. and Triyani, D. (2015) 'Analisis Dampak Pembangunan Infrastruktur Jalan Terhadap Pertumbuhan Usaha Ekonomi Rakyat Di Kota Semarang', Jurnal Dinamika Sosial Budaya, 17(1), p. 82. doi: 10.26623/jdsb.v17i1.505.

9. Permendagri (2014) Peraturan Menteri Dalam Negeri Republik Indonesia Nomor 114 Tahun 2014 Tentang Pedoman Pembangunan Desa, Lincolin Arsyad. doi: http://dx.doi.org/110.21043/equilibrium.v3i2.1268.

10. Sasmito, C. (2017) 'Implementasi Pembangunan Infrastruktur Jalan DesA', JISIP: Jurnal Ilmu Sosial dan Ilmu Politik, 6(3).

11. Sedia, I. W. (2021) 'Kepemimpinan Kepala Desa Dalam Pengelolaan Program 2019 Untuk Pelayanan Publik Di Desa Taro Kecamatan Tegallalang Kabupaten Gianyar (Kajian Komunikasi Politik)', Jurnal Ilmiah Cakrawarti, 4(1). doi: 10.47532/jic.v4i1.238.

12. Sugiyono (2015) Metode Penelitian Kualitatif dan R and D, Bandung: Alfabeta. 